\title{
Malignant mesothelioma: clustering in a family producing asbestos cement in their home
}

\author{
K E Otte, T I Sigsgaard, J Kjærulff
}

\begin{abstract}
In a family with a remarkable aggregation of malignant mesothelioma the father, mother, and a son all died of the condition, whereas two other sons and a daughter were unaffected. From 1944 to 1961 the family produced a material that was used to fix screws in drilled holes and consisted of amosite, gypsum, and sand. It was produced in the basement of their villa and was described as being a dusty job. The father died in 1984 aged 74, the son in 1985 aged 45, and the mother in 1987 aged 79 . It is concluded that there is a high risk of malignant mesothelioma after massive exposure to amosite and the risk and latency period are independent of age during the exposure.
\end{abstract}

Malignant mesothelioma is rare in Denmark, constituting less than $0.3 \%$ of all cases of cancer. ${ }^{1}$

The association between exposure to asbestos and the development of malignant mesothelioma is well

Department of Pulmonary Medicine, Vejle County Hospital, Vejle, Denmark

K E Otte, J Kjærulff

Institute of Social Medicine, Arhus University, Århus

T I Sigsgaard documented. ${ }^{2-4}$ Many authors have dealt with industrial exposure to asbestos and the risk of developing malignant mesothelioma, ${ }^{56}$ but so far as we know there have been no reports concerning massive exposure to both children and adults in a family.

We present a family of six (fig 1). The father and a son died of malignant peritoneal mesothelioma and the mother of a malignant pleural mesothelioma.

\section{Working conditions}

The family produced a compound "ROLLFIX" (fig 2) that was used to fix screws in drilled holes. The raw material was brought to the house in $100 \mathrm{~kg}$ sacks and consisted of asbestos (amosite), gypsum, and sand. By microscopic electron scanning and $x$ ray diffraction the composition was confirmed and the asbestos was found to be amosite (fig 3).

Production was carried on in the basement of their villa from 1944 to 1961 . A huge barrel was placed on the floor and the operation consisted of dry hand mixing of the components in the correct ratio. After mixing, the product was put into cans by hand (fig 4) and distributed to different stores.

The basement had no ventilation and cleaning was undertaken by the mother. No protective equipment was used at all and no special work clothes were used; only during the most dusty jobs was a coat worn.

After production had stopped the family stayed in the same residence and no attempts were made to remove asbestos from the house.

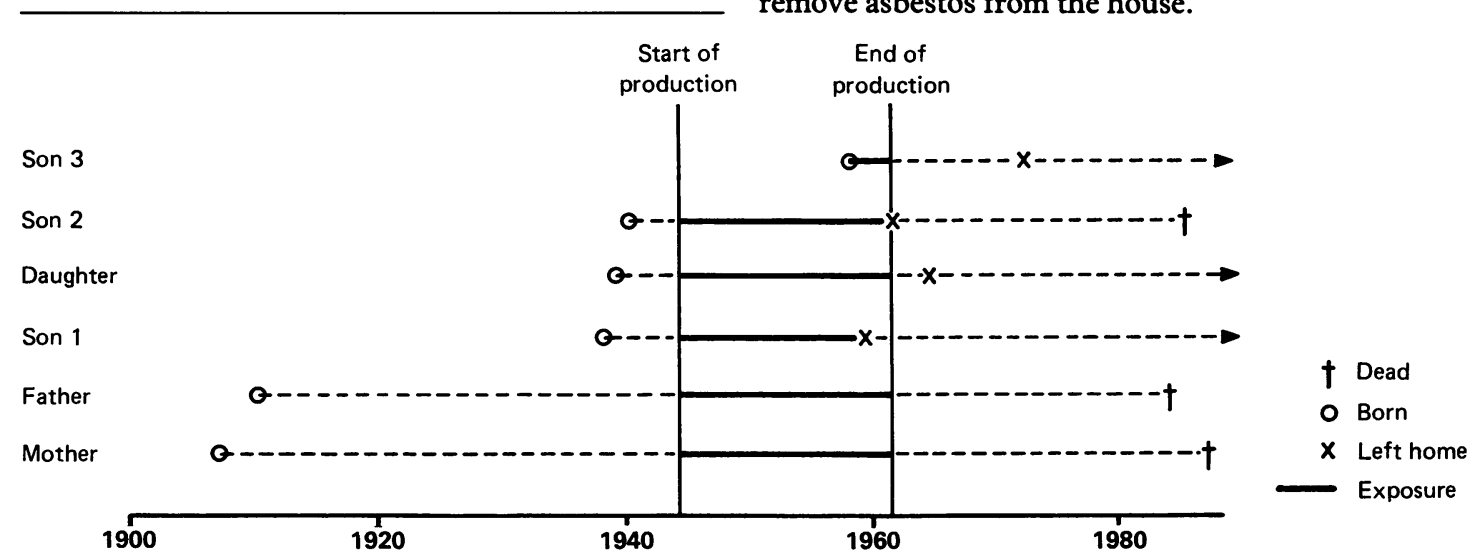

Figure 1 Relation between age, exposure, and death; in reported family. 


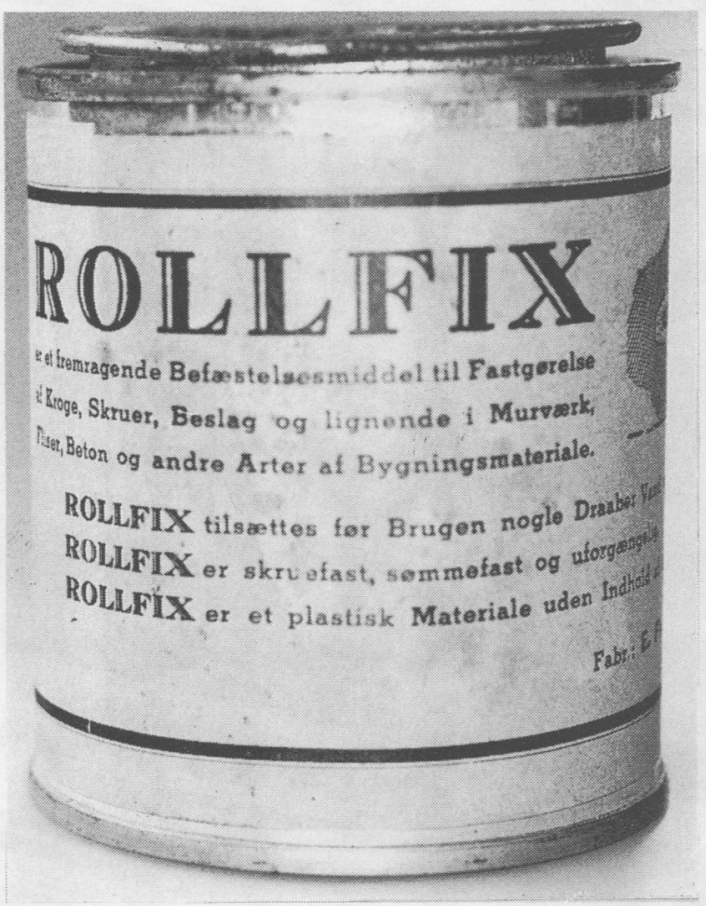

Figure 2 The product Rollfix.

\section{Case histories}

The mother was born in 1907 and was a housewife throughout her married life. In the production period she also took part in the work on a regular basis. At the age of 51 a normal chest radiograph was found. At the age of 79 she was admitted to hospital because of a pleural effusion that contained malignant cells of an adenomatous type. She was treated symptomatically but died one year later. Necropsy showed a malignant pleural tumour with local spread. Histological examination identified the tumour as a malignant mesothelioma with asbestos fibres embedded among the cells. She had smoked no more than two cheroots a day for 40 years.

The father was born in 1910. Before and after the home production he was employed as a bicycle salesman until his retirement. He had been in charge of the production and the sale of Rollfix for the whole period. He was admitted to hospital at the age of 53 with a suspected pleural tumour, having a two year history of haemoptysis. Chest radiographs showed pleural thickening and retraction of the diaphragm on the right side. The presence of a tumour was not confirmed and annual chest radiographs performed in the following years showed no changes.

He was admitted to hospital again at the age of 74 with suspected malignant disease of the gastrointestinal tract but died without a definitive diagnosis. Necropsy showed a malignant tumour of the peri- toneum spreading to the retroperitoneal nodes; histological examination showed a characteristic mesothelioma. He had smoked four cheroots a day for 60 years.

The first son, born in 1938, left home in 1959 and worked as an office clerk. He is healthy and a chest radiograph in 1987 was normal. He has smoked eight cigarettes a day for 25 years.

The daughter, born in 1939, left home in 1964. She emigrated to the United States and worked as a shop assistant. At the age of 43 a hysterectomy was performed because of carcinoma of the cervix. Chest radiographs in 1982 were normal. She has smoked 20 cigarettes a day from the age of 18 .

The second son, born in 1940, left home in 1961 and emigrated to Canada and worked in the lumber industry. He was healthy until, aged 45 , he was admitted to hospital with right subcostal pain and referred pain in the right shoulder. Ultrasound examination suggested the presence of a large solid mass occupying the right liver lobe. Chest radiographs showed some apical pleural thickening.

Laparotomy showed a large peritoneal tumour associated with massive liver metastases. Histological examination showed a malignant mesothelioma of mixed type and he died one month later. He had smoked 10 cigarettes a day from the age of 20 until the age of 32 .

The third son, born 1954, left home in 1972 to work as an office clerk. He is a non-smoker and healthy, a chest radiograph in 1987 was normal.

\section{Discussion}

We have no direct measurements of exposures in this house; fibre counting was not used during the years of production. We do, however, have fibre counts from asbestos cement factories where sacks are emptied and this procedure is comparable to the working conditions described in our family. These counts indicate a concentration of about 90 fibres/ ml. ${ }^{7}$ Seidman et al followed up a cohort of 820 men exposed to amosite asbestos from five to 40 years after the start of work. ${ }^{8}$ Most of the men had limited periods of work but some worked for several years and were exposed to amosite. They found eight cases of pleural mesothelioma and nine of peritoneal mesothelioma, all more than 20 years after the onset of work. Malignant mesothelioma was thus found in 17 of 820 workers exposed to amosite.

In our family three of the six members suffered from this condition and the explanation for this high incidence may be explained by the massive exposure and that they were exposed 24 hours a day because production took place in their home. Another reason for this familial clustering could be hereditary. Risberg et al described such a family where five of 14 family members died of malignant mesothelioma. ${ }^{9}$ 


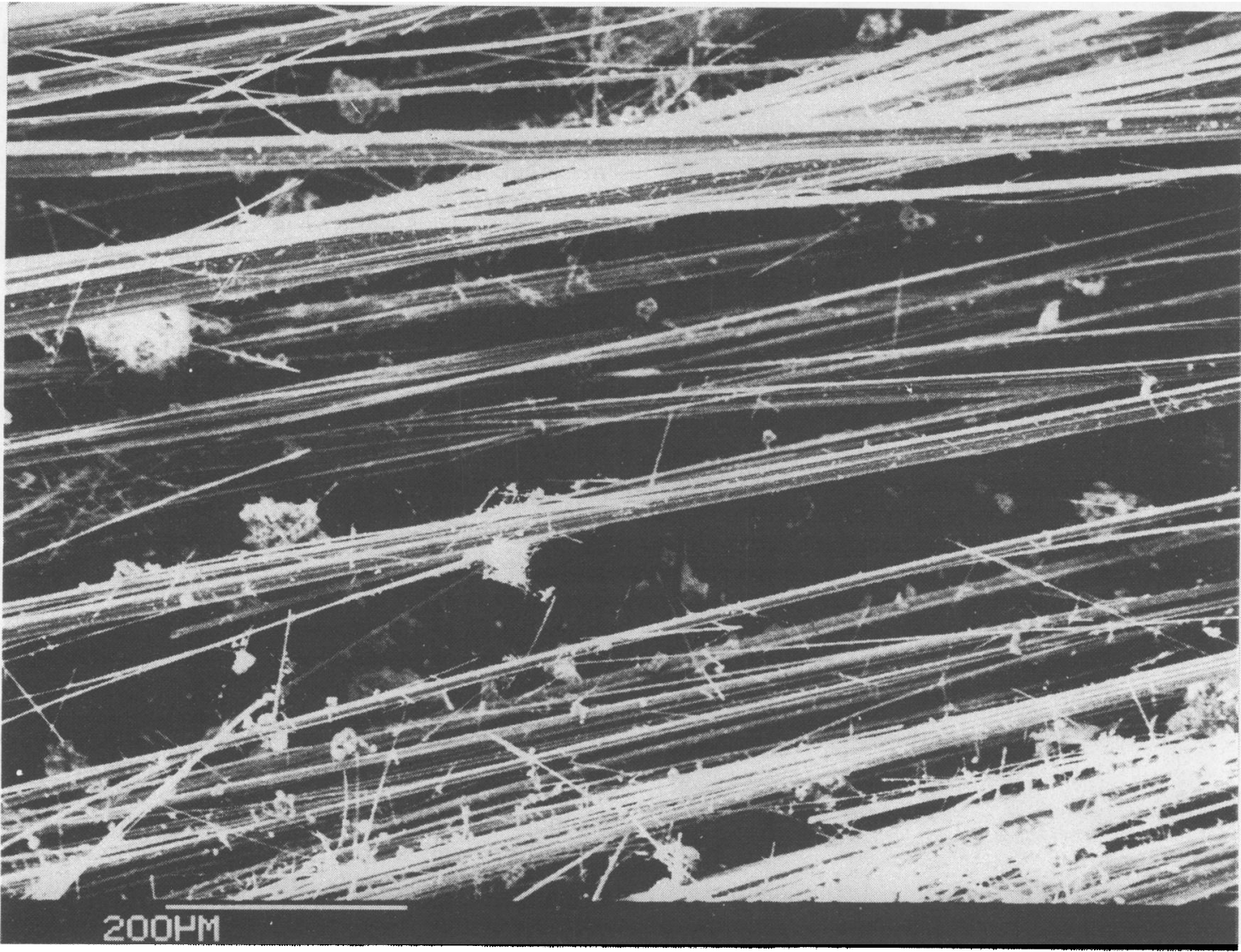

Figure 3 Electron scanning micrograph showing characteristic amosite fibres embedded in quartz.

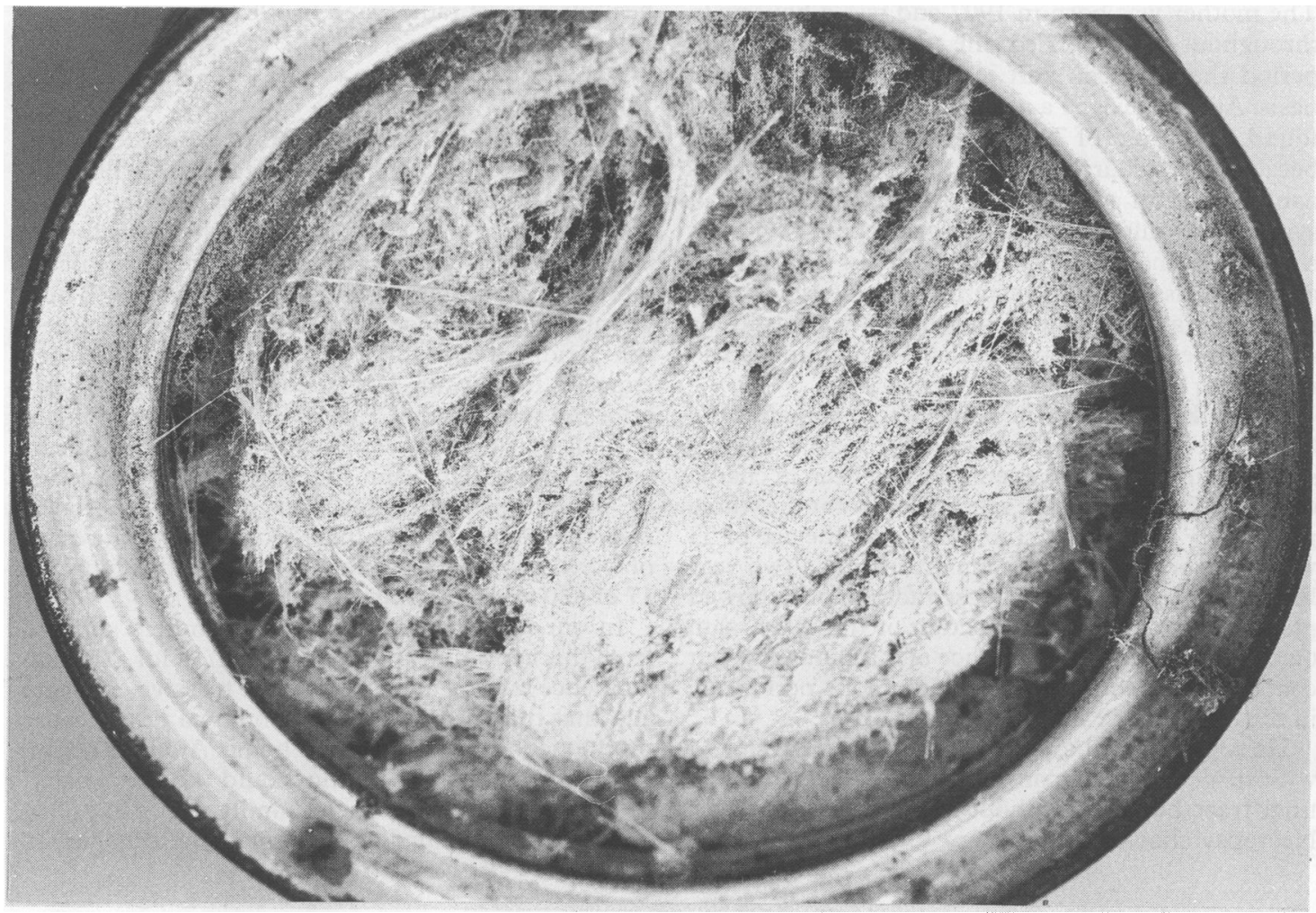

Figure 4 A tin in which "Rollfix" was distributed and sold. 
There was only mild occupational exposure in four of the cases and all the patients smoked 10-20 cigarettes a day: an additional genetic factor is necessary to explain this high incidence.

Smoking has been regarded as an important cofactor with asbestos in the genesis of malignant mesothelioma. Borrow et al found only three nonsmokers among 70 patients with malignant mesothelioma. ${ }^{6}$ By contrast, $\mathrm{McD}$ onald and $\mathrm{McD}$ Donald regarded smoking as a minor factor. ${ }^{10}$ In our family the affected members were minor smokers, but the importance of heredity in association with massive exposure cannot be ruled out, although the fact that both the father and the mother suffered from this disease makes it an unlikely cause.

Driscoll et al described a clustering of malignant mesothelioma among native American Pueblo Indians due to exposure to asbestos during the whitening of deerskin leggings for ceremonial occasions and in preparing silver jewellery using asbestos mats to protect working tables. ${ }^{11}$ This, together with our family history, emphasises the importance of a thorough examination of possible exposure to asbestos in patients suffering from malignant mesothelioma.

This report also indicates that the latency period from exposure until malignant mesothelioma develops is independent of age; the son became ill before the mother but after the father.

When the association of our three diseased family members and the home production was established, we contacted the public health authorities and the house was cleaned and the walls and floors sealed by paint to prevent any further release of fibres.

Requests for reprints to: K E Otte, Lervangen 41, 7120 Vejle Øst, Denmark.

1 Anderson M, Olsen JH. Malignant mesothelioma in Denmark 1943-1980. Ugeskr Laeger 1984;146:1085-7. (In Danish.)

2 Selikoff IJ, Churg J, Hammond EC. Relation between exposure to asbestos and mesothelioma. $N$ Engl J Med 1965;272:560-5.

3 Wagner JC, Sleggs CA, Marchand P. Diffuse pleural mesothelioma and asbestos exposure in north western Cape Province. Br J Ind Med 1960;17:260-71.

4 McNulty JC. Malignant pleural mesothelioma in asbestos workers. Med J Australia 1962;2:953-5.

5 Whitewell F, Rawcliffe RM. Diffuse malignant pleural mesothelioma and asbestos exposure. Thorax 1971;26:6-22.

6 Borrow M, Conston A, Livornese L, et al. Mesothelioma following exposure to asbestos: a review of 72 cases. Chest 1973;64:641-6.

7 Hurst G, Spivey C, Matlaye $\mathbb{W}$, et al. The Tyler asbestos workers program. Arch Environ Health 1979;34:432-9.

8 Seidman H, Selikoff IJ, Gelp SK. Mortality experience of amosite asbestos factory workers: dose-response relationships 5-40 years after onset of short-term work exposure. Am J Ind Med 1986;10:479-514.

9 Risberg B, Nickels J, Wägermark J. Familial clustering of malignant mesothelioma. Cancer 1980;45:2422-7.

$10 \mathrm{McDonald}$ A, McDonald JC. Epidemiological surveillance of mesothelioma in Canada. Can Med Assoc J 1973;109:359-62.

11 Driscoll RJ, Mulligan WJ, Schultz D, Candelaria A. Malignant mesothelioma, a cluster in a native American pueblo. $N$ Engl $J$ Med 1988;318:1437-8.

Accepted 13 March 1989 